\title{
Health secretary under attack over centralization plan
}

\section{Erika Check, Washington}

Tommy Thompson, the US health secretary, is under heavy fire this week for his farreaching plan to streamline public and Congressional relations at the National Institutes of Health (NIH) and other parts of his sprawling department.

Thompson wants enquiries to all parts of the Department of Health and Human Services (HHS) - including the Food and Drug Administration, the Centers for Disease Control and Prevention (CDC) and all the institutes of the NIH - to pass through new, centralized departments under his control.

Health-department officials say that the reorganization will help them to present clearer, more coherent messages on crucial science and health matters. "We've been working since we got here to try to create a more unified department and a more responsive structure," says Kevin Keane, assistant secretary for public affairs at the HHS.

But supporters of the various agencies are deeply concerned that the change would damage the institutes' credibility with the public and Congress. "Information from the $\mathrm{NIH}$ has been highly valued for many years because it is viewed as a bipartisan institution with no political agenda," says Harold

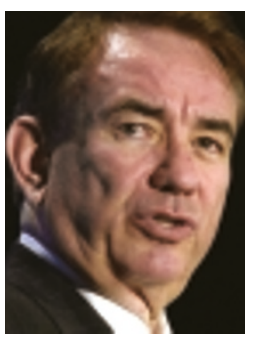

Tommy Thompson wants to see a more unified structure.
Varmus, former director of the NIH.

The restructuring is expected to form part of the budget proposal for the 2003 fiscal year, which will be sent to Congress by President Bush in early February. Strong objections are expected, and Congressional staff are already on the attack. "We need free and unfettered access to the various agencies," says one Democrat aide in the Senate.

Earlier efforts by Thompson to direct press and public enquiries through his office caused problems last autumn, when CDC and NIH officials were told to steer questions on anthrax through it. As a result, critics claim, the public did not receive accurate and timely information during a series of anthrax attacks.

But Keane claims that fears over restricted access to scientific information are unfounded. "We're just trying to handle communications efficiently so there will be a clear place to turn to for what people need, and a clearer answer coming back," he says.

\section{Astronomer set to star in Taiwan}

\section{David Cyranoski, Tokyo}

Taiwan has enticed Frank Shu, a leading astronomer in the United States, to take up the post of president at the National Tsinghua University in Hsinchu.

Shu, who is based at the University of California, Berkeley, is a prominent theorist and former president of the American Astronomical Society.

Taiwanese government officials see Shu's

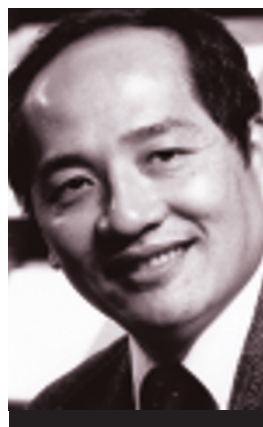

Frank Shu sees scope for growth at Tsinghua in Taiwan. appointment as a significant coup for its university system. Shu says that his move is motivated by one basic assessment: "I thought I could make a bigger difference in Taiwan." Working with C. C. Lin at the Massachusetts Institute of Technology, Shu in 1964 proposed the spiral density wave theory, which provided the first quantitative model for understanding how spiral galaxies form. He went on to examine the interstellar medium, planetary rings and, more recently, star formation and meteorites.

"The proper role of the university president is to serve faculty and students," Shu says, pledging to continue his research at Tsinghua, "and you can only have the necessary understanding if you are down in the trenches yourself." He aims to make the university bilingual, with courses offered in Chinese and English.

Shu's move "will help to recruit better talent to Taiwan and Asia", says Fred Lo, director of the Institute of Astronomy and Astrophysics in Taipei. The appointment "will also have influence beyond the university campus and beyond astronomy", he adds.

Born in China, but raised in the United States, Shu is following a precedent. At 58, Shu's current age, his father took over the presidency of Tsinghua university and helped to develop the neighbouring Hsinchu Science-based Industrial Park that gave rise to Taiwan's electronics industry.

\section{Allegations of police surveillance prompt calls for inquiry}

\section{Sally Goodman, Paris}

INSERM, France's main biomedical research agency, has been asked to investigate allegations that one of its laboratories came under police surveillance because of its work on the role of dietary salt in heart disease.

The allegations, which have been emphatically denied by the French authorities, appeared in the 11 January edition of Le Point, one of France's leading weekly news magazines.

The magazine says that in May 2000, the police received an order from an unknown source to tap the telephone of Pierre Meneton, a researcher at INSERM's laboratory of physiology and experimental vascular pathology in Paris. That was shortly after Meneton handed a report to the French food-safety agency, AFSSA, in which he accused the food industry of "poisoning" consumers because of excess salt in its products.

Meneton was surprised by the allegations in Le Point. "I will be asking for a full investigation and if there is any truth in the matter I will be lodging an official complaint," he says.

The relationship between salt intake and high blood pressure has long been the subject of fierce scientific argument. Publication of the allegations coincided with an international conference in Paris on salt and health, organized by the AFSSA in response to Meneton's report. An advisory panel set up by the agency told the meeting that the salt content in processed food should be cut by $20 \%$ over five years.

Le Point claimed that a member of the panel, Joël Ménard, a former chief health officer in the French government, has also been under police surveillance. But Ménard is sceptical. "I can't believe it's true," he says. "If there is any truth in it, then French democracy is dead."

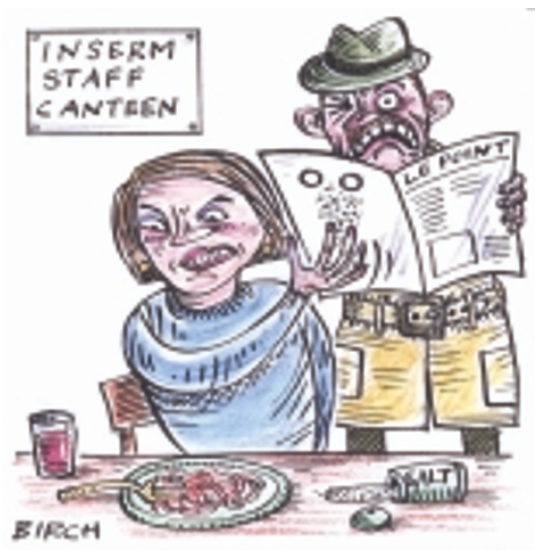

